Proc. Indian Acad. Sci. (Chem. Sci.), Vol. 102, No. 5, October 1990, pp. 687-691.

() Printed in India

\title{
Vibrational Raman spectra of some substituted uracils
}

\author{
J N RAI \\ Department of Physics, University of Gorakhpur, Gorakhpur 273009, India
}

\begin{abstract}
Vibrational assignments of the frequencies of 6-azauracil, 5-fluorouracil, 5-bromouracil and 6-azathymine have been made with the help of their Raman and infrared spectra. Raman spectra of these molecules were recorded in the range $75-4000 \mathrm{~cm}^{-1}$. The near infrared spectra of these molecules were also recorded in the $400-4000 \mathrm{~cm}^{-1}$ range using the nujol mull technique. The vibrational frequencies have been noted and the vibrational assignments have been made on the basis of the group frequency approach. The assignments have also been facilitated by comparison with the frequencies of similar molecules.
\end{abstract}

Keywords. Vibrational Raman spectra; substituted uracils; group frequency approach.

\section{Introduction}

$\mathrm{N}$-heterocyclic molecules are of great biological importance because they play a significant role in the structural problems of nucleic acids. These molecules are obtained by substituting an $\mathrm{N}$ atom for the $\mathrm{CH}$ group in aromatic cyclic compounds. Pyrimidine and substituted pyrimidies are important $\mathrm{N}$-heterocyclic molecules. Some of the substituted pyrimidines have been studied spectroscopically. Austin (1934), Platt (1950), Marshall and Walker (1951), Brown et al (1955), and Mason (1959) have studied the absorption spectra of different pyrimidine substituents. The vibrational spectra of uracil (Lord and Thomas 1967; Susi and Ard 1971; Nishimura et al 1981), cytosine (Susi and Ard 1974), 6-azauracil and 5-fluorouracil (Rai 1983), dihydroxypyrimidine (Srivastava et al 1984) and dimethylpyrimidines (Srivastava et al 1985) have been studied in great detail. The present communication reports the vibrational spectra of 6-azauracil, 5-fluorouracil, 5-bromouracil and 6-azathymine molecules.

\section{Experimental}

The samples of these molecules were procured from Sigma Chemical Company and used without further purification. The infrared absorption spectra of the chemicals were recorded on a CZ Specord IR 75 double beam spectrophotometer using the nujol mull technique in the region $400-4000 \mathrm{~cm}^{-1}$. Raman spectra of these molecules were recorded on a Jobin-Yuon spectrophotometer coupled with an argon ion source (Coherent Innova 70 laser source) in the range $75-4000 \mathrm{~cm}^{-1}$ (figures 1-4). A correlation of the fundamental frequencies $\left(\mathrm{cm}^{-1}\right)$ of the four molecules along with their parent molecule uracil (Susi and Ard 1971) is given in table 1. 


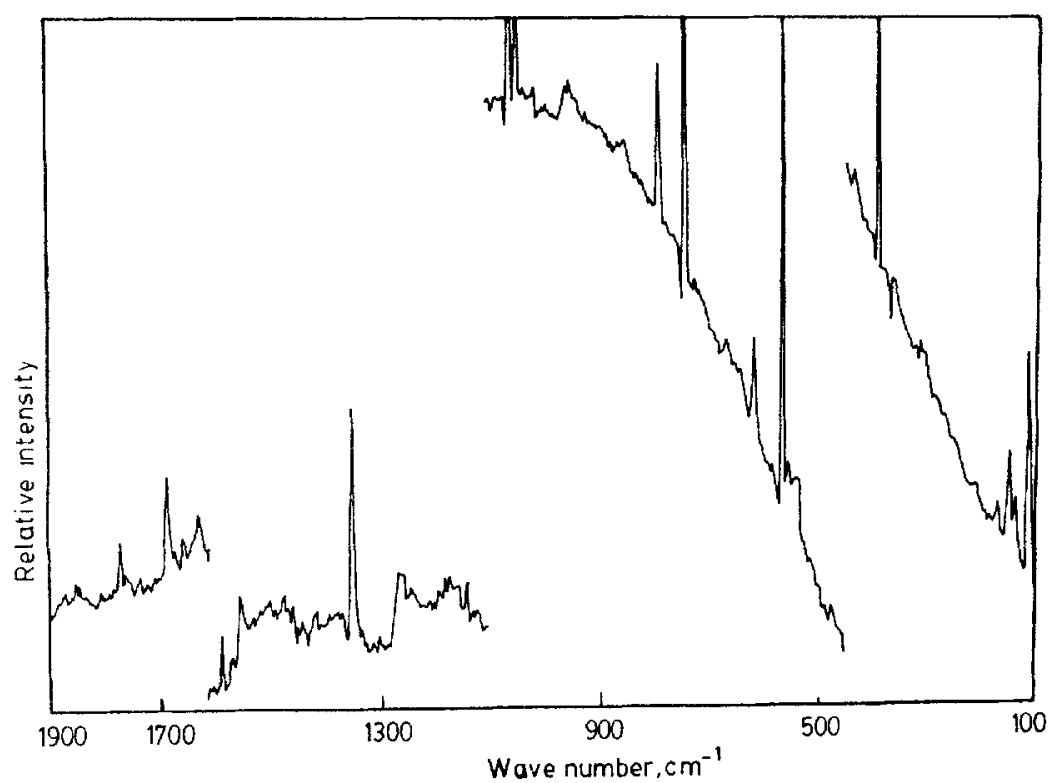

Figure 1. Raman spectrum of 5-bromouracil.

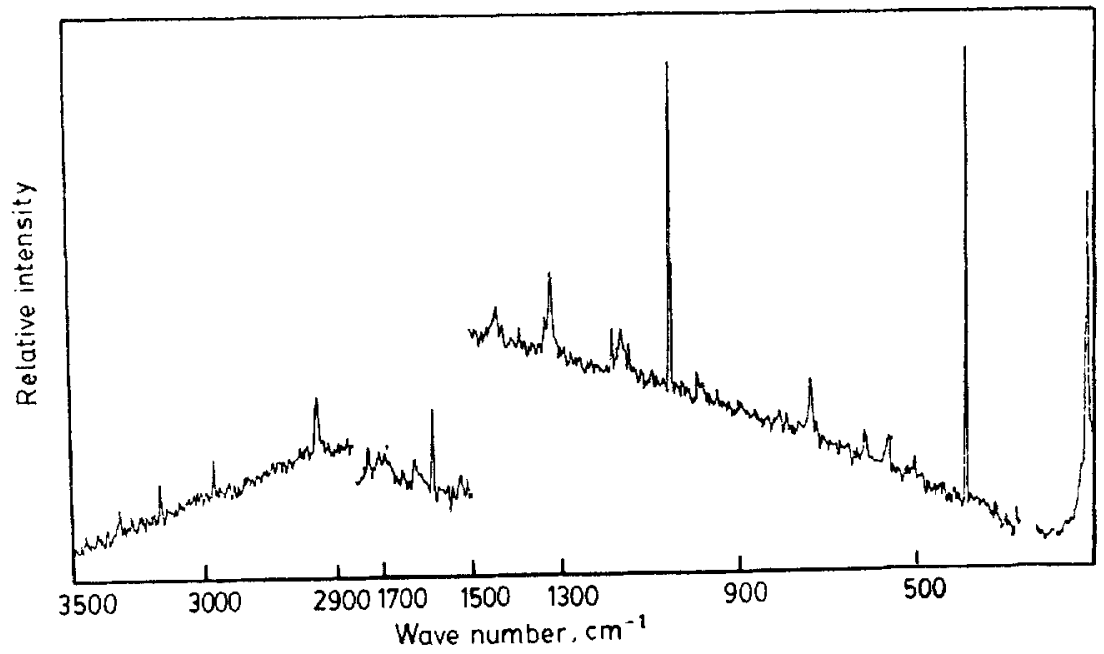

Figure 2. Raman spectrum of 6-azathymine.

\section{Discussion}

The molecules 6-azauracil, 5-fluorouracil, 5-bromouracil and 6-azathymine have only one element of symmetry each i.e. a plane of reflection. Thus, they belong to the $C_{s}$ point group. They have only $a^{\prime}$ (totally symmetric vibrations and $a^{\prime \prime}$ (non-totally symmetric vibrations). 


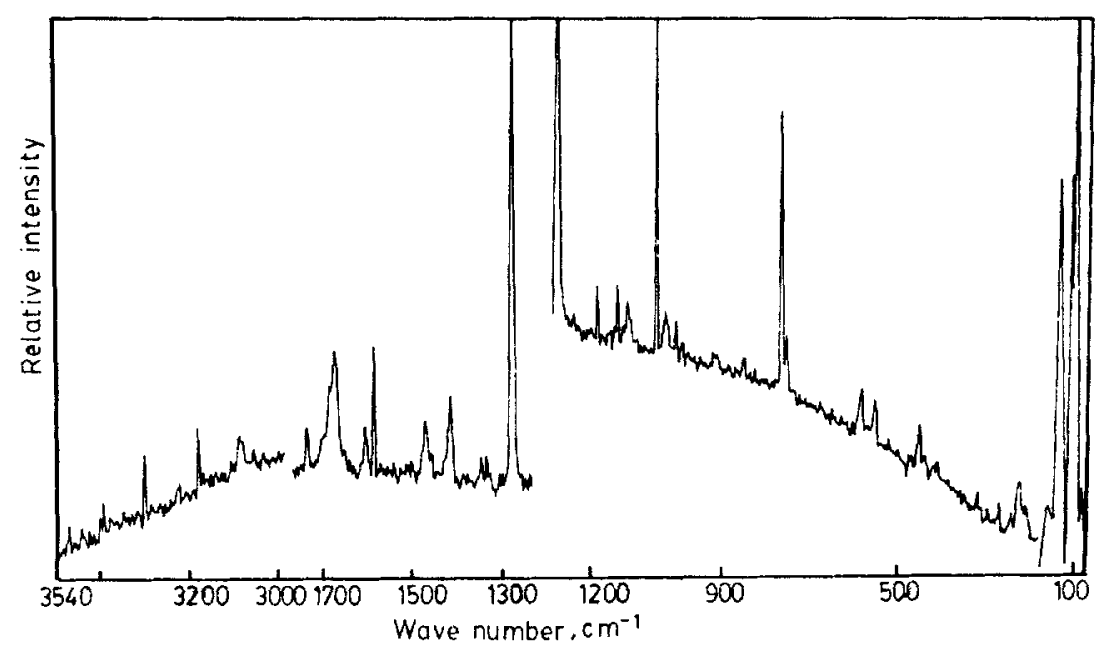

Figure 3. Raman spectrum of 6-azauracil.

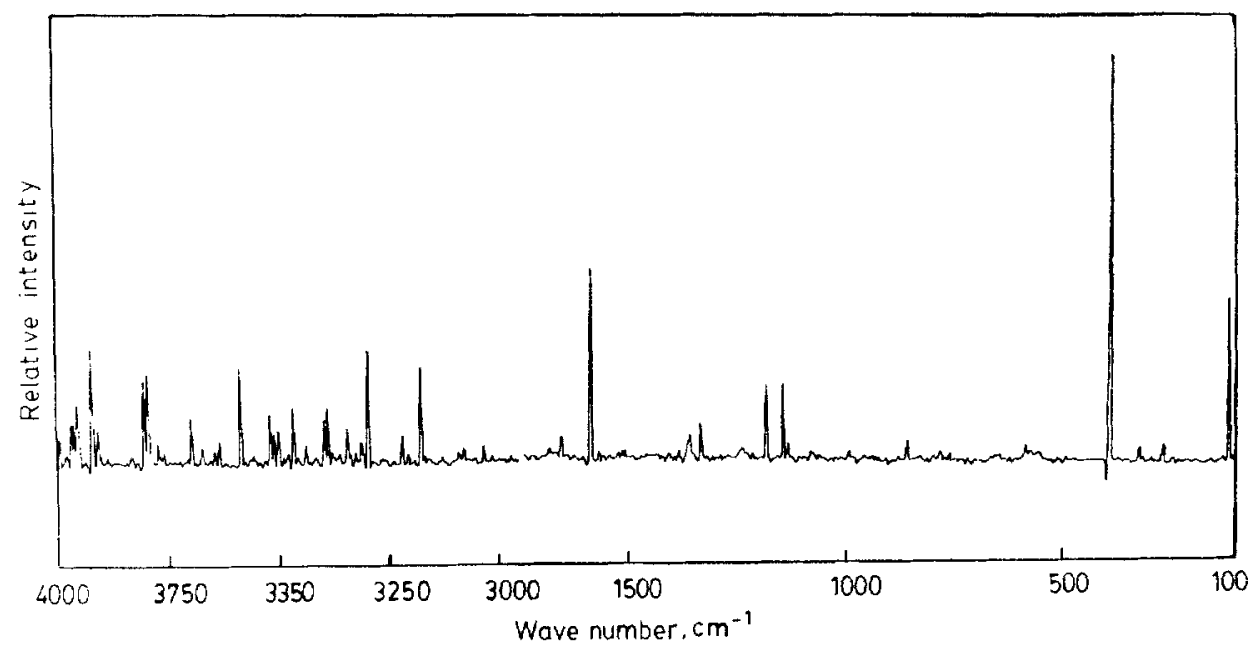

Figure 4. Raman spectrum of 5-fluorouracil.

The vibrational assignment of the observed frequencies of the molecules were made as per Lord and Thomas (1967) Susi and Ard (1971, 1974), Sanyal et al (1977), Durig and Little (1981) and Rai (1983). The assignments are based mainly on the concept of the characteristic frequencies associated with vibrations of groups of atomic nuclei with a molecule.

Investigations of the infrared spectra of compounds 6-azauracil, 5-fluorouracil, 5 -bromouracil and 6-azathymine show very strong bands around $1500 \mathrm{~cm}^{-1}$. These bands are due to the $\mathrm{C}=\mathrm{O}, \mathrm{C}=\mathrm{N}, \mathrm{C}=\mathrm{C}$ and $\mathrm{N}=\mathrm{N}$ stretching vibrations. The bands in the region $1500-1200 \mathrm{~cm}^{-1}$ correspond to various types of stretching motions involving $\mathrm{C}-\mathrm{C}, \mathrm{C}-\mathrm{N}$ and $\mathrm{N}-\mathrm{N}$ single bonds. 
Table 1. Correlation of the fundamental vibrations $\left(\mathrm{cm}^{-1}\right)$ of uracil, 5-fluorouracil, 5-bromouracil, 6-azauracil and 6-azathymine.

\begin{tabular}{|c|c|c|c|c|c|}
\hline Uracil & $\begin{array}{l}\text { 5-Fluoro- } \\
\text { uracil }\end{array}$ & $\begin{array}{l}\text { 5-Bromo- } \\
\text { uracil }\end{array}$ & $\begin{array}{l}\text { 6-Aza- } \\
\text { uracil }\end{array}$ & $\begin{array}{l}\text { 6-Azathy- } \\
\text { mine }\end{array}$ & Assignments \\
\hline 398 & 405 & 390 & 400 & 390 & $\gamma \mathrm{C}=\mathrm{O}$ \\
\hline 435 & 450 & 425 & 450 & 464 & yring \\
\hline 550 & - & - & 540 & 535 & $\delta$ ring \\
\hline 565 & 550 & 560 & 550 & 566 & $\delta \mathrm{C}=\mathrm{O}$ \\
\hline 600 & 620 & 580 & 585 & 580 & $\delta$ ring \\
\hline 760 & 750 & 750 & 740 & 737 & $\gamma \mathrm{CH}$ \\
\hline 781 & 760 & 783 & 760 & 780 & $\delta$ ring \\
\hline 822 & - & - & - & - & $\gamma \mathrm{CH}$ \\
\hline 851 & 880 & 872 & 850 & 850 & $\gamma \mathbf{N H}$ \\
\hline 993 & 950 & 1008 & 990 & 950 & $\delta$ ring \\
\hline 1003 & 1000 & 1060 & 1010 & 1010 & $v$ ring \\
\hline 1099 & - & - & 1105 & 1120 & $v$ ring \\
\hline 1238 & 1260 & 1255 & 1260 & 1205 & $v$ ring \\
\hline 1390 & 1380 & 1350 & 1370 & - & $\delta \mathrm{CH}$ \\
\hline 1417 & 1430 & 1427 & 1420 & 1410 & $\delta \mathrm{NH}$ \\
\hline 1453 & 1460 & 1447 & 1460 & 1450 & $v$ ring \\
\hline 1508 & 1500 & 1496 & 1525 & 1525 & $\delta \mathrm{NH}$ \\
\hline 1611 & - & - & 1605 & 1590 & $v \mathrm{C}=\mathrm{N}$ \\
\hline 1675 & 1660 & 1675 & 1650 & 1675 & $v \mathrm{C}=\mathrm{O}$ \\
\hline 1760 & 1720 & 1770 & 1725 & 1720 & $v \mathrm{C}=\mathrm{O}$ \\
\hline 3080 & 1250 & 545 & 3085 & 2872 & $v \mathrm{CX}$ \\
\hline 3100 & 3120 & 3058 & 3085 & 2965 & $v \mathrm{CH}$ \\
\hline 3160 & 3175 & 3098 & 3160 & 3140 & $v \mathrm{NH}$ \\
\hline 3160 & 3420 & 3178 & 3380 & 3175 & $v \mathbf{N H}$ \\
\hline
\end{tabular}

The molecule 6-azathymine possesses a methyl group. The infrared peaks can be picked up very easily as due to various methyl group vibrations. Bands at 2872 and $2965 \mathrm{~cm}^{-1}$ are due to symmetric and antisymmetric methyl C-H stretching vibrations, respectively. The bands at 1350 and $1450 \mathrm{~cm}^{-1}$ are due to $\mathrm{CH}_{3}$ deformation modes. The $\mathrm{CH}_{3}$ rocking mode appears at $950 \mathrm{~cm}^{-1}$.

$\mathrm{C}-\mathrm{H}$ and $\mathrm{N}-\mathrm{H}$ stretching vibrations appear around $3000 \mathrm{~cm}^{-1}$. Except for 6-azathymine, the three other molecules, viz. 6-azauracil, 5-fluorouracil and 5-bromouracil, have one $\mathrm{C}-\mathrm{H}$ stretching vibration each. Similarly, all the four molecules possess two frequencies around $3200 \mathrm{~cm}^{-1}$ due to $\mathrm{N}-\mathrm{H}$ stretching vibrations. In addition to these assignments, the other frequencies are also assigned and are listed in table 1 .

\section{Acknowledgement}

The author is grateful to the Regional Sophisticated Instrumentation Centre, Bombay, for recording the Raman spectra, to Dr. S L Srivastava for the infrared spectra and to the University Grants Commission for financial assistance. 


\section{References}

Austin J E $1934 \mathrm{~J}$. Am. Chem. Soc. 562141

Brown D J, Hoorger E and Mason S F 1955 J. Chem. Soc. 4035

Durig J R and Little T S 1981 J. Chem. Phys. 753660

Lord R C and Thomas G J 1967 Spectrochim. Acta A23 2551

Marshall J R and Walker J J 1951 J. Chem. Soc. 1004

Mason S F 1959 J. Chem. Soc. 1247

Nishimura Y, Tsuloi M, Kato S and Morokema K 1981 J. Am. Chem. Soc. 1031354

Platt J R 1950 J. Chem. Phys. 151168

Rai J N 1983 Indian J. Phys. B57 241

Susi H and Ard J S 1971 Spectrochim. Acta A27 1549

Susi H and Ard J S 1974 Spectrochim. Acta A30 1848

Sanyal N K, Srivastava S L and Goel R K 1977 Indian J. Pure Appl. Phys. 15108

Srivastava S L, Prasad M, Rohitasva and Pandey V S 1984 Spectrochim. Acta A40 675

Srivastava S L, Prasad M and Singh H S 1985 Indian J. Phys. B59 29 